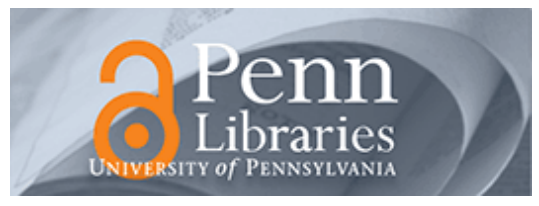

University of Pennsylvania

ScholarlyCommons

Management Papers

Wharton Faculty Research

$10-2006$

\title{
Industry Evolution Through Consolidation: Implications for Addiction Treatment.
}

\author{
Rafael A. Corredoira \\ John R. Kimberly \\ University of Pennsylvania
}

Follow this and additional works at: https://repository.upenn.edu/mgmt_papers

Part of the Health Services Administration Commons, Health Services Research Commons, and the Performance Management Commons

\section{Recommended Citation}

Corredoira, R. A., \& Kimberly, J. R. (2006). Industry Evolution Through Consolidation: Implications for Addiction Treatment.. Journal of Substance Abuse Treatment, 31 (3), 255-265. http://dx.doi.org/10.1016/ j.jsat.2006.06.020

This paper is posted at ScholarlyCommons. https://repository.upenn.edu/mgmt_papers/163

For more information, please contact repository@pobox.upenn.edu. 


\title{
Industry Evolution Through Consolidation: Implications for Addiction Treatment.
}

\begin{abstract}
Drawing on experiences in other industries, this article argues that the business of addiction treatment is likely to be transformed by the advent of a period of consolidation, in which a number of small independent programs will be acquired by larger, better capitalized, and managerially more sophisticated enterprises. Consolidation will be driven by opportunities to leverage new technologies, to exploit new regulatory initiatives, and to introduce economies of scale and scope into an industry that is currently highly fragmented. The process is likely to result in segmentation of the market, with the coexistence of large, generalist, highly standardized firms and a number of small highly specialized firms. When an industry consolidates, the types and quality of services provided can improve through the adoption of best practices and through increased competition among larger providers. If these larger providers are publicly traded, however, efforts to improve will inevitably be influenced by pressures to maintain or increase quarter-to-quarter earnings and share prices, leaving open the long-term impact on service quality.
\end{abstract}

\section{Keywords}

humans, industry, managed care programs, marketing of health services, substance abuse treatment centers, substance-related disorders

Disciplines

Health Services Administration | Health Services Research | Performance Management 


\title{
INDUSTRY EVOLUTION THROUGH CONSOLIDATION: IMPLICATIONS FOR ADDICTION TREATMENT
}

\author{
Rafael A. Corredoira \\ The Wharton School \\ University of Pennsylvania \\ Philadelphia, PA \\ corredoi@wharton.upenn.edu \\ John R. Kimberly \\ The Wharton School \\ University of Pennsylvania \\ Philadelphia, PA \\ kimberly@wharton.upenn.edu
}

\begin{abstract}
APRIL 2006
Accepted for publication on 2006 JSAT Special Issue
\end{abstract}

The authors thank Tom McLellan for his valuable editorial assistance, and Victor Capoccia and participants at "The Wharton-TRI-COMAT Conference on the Business of Addiction Treatment" for their comments on earlier versions of this paper. Rafael Corredoira would like to thank TRI for financial support received under grant \#45771 funded by the Robert Wood Johnson Foundation. Any errors and omissions remain our own. 


\begin{abstract}
Drawing on experiences in other industries, this paper argues that the business of addiction treatment is likely to be transformed by the advent of a period of consolidation, in which a number of small, independent programs will be acquired by larger, better-capitalized, and managerially more sophisticated enterprises. Consolidation will be driven by opportunities to leverage new technologies, to exploit new regulatory initiatives, and to introduce economies of scale and scope into an industry that is currently highly fragmented. The process is likely to result in segmentation of the market, with the coexistence of large, generalist, highly standardized firms and a number of small, highly specialized firms. When an industry consolidates, the types and quality of services provided can improve through the adoption of best practices and through increased competition among larger providers. If these larger providers are publicly traded, however, efforts to improve will inevitably be influenced by pressures to maintain or increase quarter-to-quarter earnings and share price, leaving open the long term impact on service quality.
\end{abstract}




\section{INTRODUCTION}

The history of industrial evolution contains many lessons that are relevant today in general and in particular to the addiction treatment field. Patterns can be observed in the way industries have evolved, and these patterns can help us anticipate likely trajectories for industries such as addiction treatment in the future. Historically there are two kinds of transformational forces that affect an industry.

Transformational Change from Outside the Field - First, there are fundamental, even revolutionary changes that are propelled by technologicalinnovation. New, transformational technologies, however, are frequently not applied or even recognized by the dominant firms in an established industry, typically because those new technologies cannot be easily merged with their firms' established methods and because they threaten their established markets. Examples of highly successful firms being unable to anticipate or recognize important innovations abound, as Christiansen (1997) and many others have observed. One has to go no further than the telephone or the camera to get a sense of the argument. AT\&T dominated both the local and the long distance telephone markets for decades, but following the break-up in the 1980's it stumbled badly and was unable to maintain its technological or distributional leadership. Polaroid dominated the film-based instant photography industry for decades, but had great difficulty anticipating the impact of digital technology and making the transition away from film and into the digital environment (Tripsas \& Gavetti, 2000). For the addiction treatment industry, the implication is that significant transformation is possible; that it is likely to be driven by technological innovation and that it is likely to be stimulated by developments outside the field 
as we know it today. New organizations (and perhaps new organizational forms), are likely to be leaders in the transformation process. Such significant transformation may be just around the corner or may be years in the making. The technological innovations that may lead to transformational change are difficult to predict and thus will not be the focus of the present paper. Instead, we pay attention to existing innovations that, applied to field, have the potential to stimulate change. We use the lessons of history to anticipate the types of improvement in managerial processes and in quality of services provided as the addiction treatment industry goes through a period of consolidation.

Change From Within an Industry Through Consolidation - Consolidation occurs in the evolution of every industry. Industries tend to follow a life cycle, with a stage of rapid growth initially, characterized by the entry of a large number of firms and a relatively small exit rate. This is followed by a plateau, where the rates of entry and exit are similar. This plateau is typically followed by a shakeout period, where a large number of firms exit or are merged with existing competitors. Finally, the industry population stabilizes with a smaller number of firms and lower entry and exit rates.

The processes of firm growth that lead ultimately to consolidation within an industry are generally of two types:

a) Organic growth, when a firm grows by expanding its capabilities and routines internally. 
b) Growth through acquisition, when a firm buys-out competitors in order to grow and exploit unrealized opportunities (such as exploitation of market power, technological or managerial advantages).

Organic growth is likely to result in consolidation in the long run, as the emergence of leadership and market dominance by large firms slows down new entry into the industry and increases the exit rate. Growth through acquisition, on the other hand, results in industry consolidation in a relatively short period of time. In this paper we pay particular attention to "roll-ups", a form of horizontal consolidation in which a single firm acquires a large number of similar competitors, and that typically occurs in a relatively short period of time, often due to a change in regulations by government.

An instructive example of rapid consolidation comes from the early $20^{\text {th }}$ century case of General Motors. In 1908, GM was founded as a holding company for Buick, then controlled by William C. Durant. It acquired Oldsmobile later that year, and the next year, acquired Cadillac, Elmore, and Oakland. By 1920, GM had acquired many other small car and auto part manufacturers, acquisitions that in Durant's view were no more than acquiring patents and plants to satisfy an ever-expanding market. The goal of GM, in a market driven by demand, was to expand production and distribution, without concern for costs or administrative capabilities. The crisis of the 1920s found GM in a poor position to face a dramatic drop in demand. During the 1920's the ability to produce at lower cost became crucial and the lack of administrative capabilities to manage costs and quality forced Durant to sell GM to the DuPont family. The gap in administrative capabilities was closed by the DuPonts by introducing standard, state-of-the-art administrative practices across the different subsidiaries. In so doing they were able to turn GM 
around. To summarize, the consolidation in the automotive industry that GM led in the early 1900s was initially motivated by an interest in controlling and diffusing new technology across the entire company and in securing market access. However, in the 1920s, continued profit opportunities resided in the ability to adopt improved administrative practices and to diffuse them across the subsidiaries.

A similar case is found in the tobacco industry where the American Tobacco Company (ATC) was created in 1890, a trust owned by James B. Duke, as a roll-up that included more than 200 small firms. In this case the roll-up motivation was technology (new packaging systems), market access and buying power. Interestingly, this roll-up was too successful. The resulting market

power for ATC led tobacco planters early in the $20^{\text {th }}$ century to form the Dark Tobacco District Planters' Protective Association of Kentucky and Tennessee, in an attempt to counter ATC's power. As a result, in 1911, ATC was broken up by an antitrust action.

\section{WHAT ARE THE ENVIRONMENTAL FACTORS THAT PROMOTE ROLL-UPS?}

Roll-ups in particular and industry consolidation in general occur in response to opportunities deriving from sources such as technological innovation, regulation, finance, and bargaining power.

TECHNOLOGICAL INNOVATION. When new technology provides superior performance relative to the existing technology, the unrealized benefits create a profit opportunity through consolidation. Here we refer to technology quite broadly; we do not just include manufacturing technology, or in the case of the health industry, treatments, equipment or medication - but also administrative 
and operational practices. For example, in the automobile industry firms have become more competitive by adopting JIT (just-in-time) and lean manufacturing practices, administrative and operational procedures that can lead to improved quality at reduced costs.

Roll-ups are possible, in part, because of the natural inertia of incumbent firms. The adoption of new technology is imbued with a great deal of uncertainty, and managers have a tendency to stick to what is known and to avoid the new and untested. Firms with underperforming technology become targets for those possessing a new technology because the acquiring firms can obtain higher profit margins by reducing costs when introducing the new systems.

REGULATION can be either a facilitator of or an obstacle to roll-ups. As we saw in the case of the anti-trust ruling in the tobacco industry, regulation can impede the emergence of roll-ups. On the other hand, regulatory changes can also create consolidation opportunities, as in the case of the banking industry or the airline industry. In 1980, for example, the Depository Institutions Deregulation and Monetary Control Act allowed banks to merge across state lines. It thus provided an opportunity for those with advanced technology to target underperforming banks for purchase, then transfer the advanced technology and benefit from the improved performance. BankOne, for example, took advantage of this legislation and developed the ability to transfer its above average expertise and knowledge in the areas of operations and information systems into acquisitions, thereby realizing the economic benefits (Szulanski, 2001; Winter \& Szulanski, 2001). 
FINANCING. Financing is usually a major constraint for small firms, particularly in expanding markets. The roll-up of small firms into a larger organization can provide the size needed to access financial markets.

INCREASED BARGAINING POWER. By becoming a larger customer or supplier, the bargaining position of the acquiring firm is improved. An example would be HMOs, which are able to negotiate better prices from health providers than any individual patient or employer due to the business volume they bring to a service provider included in their "network." Bargaining power is relevant not only as a customer but also as a supplier, as in the case of OPEC, where oil producers, by creating a cartel, have been able to influence the price of oil. A recurrent pattern in the evolution of industries is that consolidation at one stage in the value chain creates a chain reaction. Usually, customers react to supplier consolidation by consolidating themselves in order to counter the bargaining power of their suppliers. In a similar manner, suppliers also react to customer consolidation in the same way - as we saw in the case of the tobacco industry in the early 1900’s.

\section{WHAT ARE THE STRATEGIC OBJECTIVES OF ROLL-UPS?}

McKelvey (1999) discusses three strategic objectives in industry roll-ups: economies of scale, value-cost leveraging and redefining products or services (see Figure 1). He presents examples of strategic objectives for different industries and the criteria utilized to identify targets to acquire (see Figure 2) that illustrate the points made in this section.

\section{INSERT FIGURE 1 ABOUT HERE}




\section{INSERT FIGURE 2 ABOUT HERE}

ECONOMIES OF SCALE AND SCOPE. Consolidation within an industry opens the opportunity to exploit economies of scale by providing services and products to a larger customer base. This, in turn leads to reduced fixed costs per unit manufactured or serviced, since from an administrative point of view, the cost of supporting activities usually does not increase in direct proportion to the number of services provided. In addition, the increased number of business firms acquired through consolidation can provide valuable new information and a learning opportunity that reduces costs and waste (learning curve). Also deriving from economies of scale are the benefits that accrue in operations and services from the mastery gained by people performing the service more times. This repetition usually reduces errors and improves quality, a fact that has been well documented (Huckman \& Pisano, forthcoming; Pisano, Bohmer, \& Edmondson, 2001).

Consolidation also provides opportunities to exploit economies of scope. A larger customer base can justify the provision of a range of services that would not be feasible for a smaller clientele. For example, the new, larger organization can create a specialized unit to centralize the provision of a particular service, when it is not profitable to provide it in a decentralized manner, and refer the clients to the specialized unit in order to achieve economies of scope. Through unit specialization, firms can increase the scope of services provided while taking advantage of the quality and cost improvements derived from specialization itself. 
INFORMATION SHARING. There are several information-related benefits that can accrue to the firm that has acquired or consolidated other firms. First, a larger amount of information may reach the organization from different geographic locations, providing information about market tendencies and other forms of feedback. Second, information gleaned from experiential learning can be shared across the whole organization, and practices and solutions can be tried in different environments, helping management understand what works and what does not and why. Finally, the larger number of cases with which the organization has direct experience may facilitate better understanding of the causal connections between organizational action and resulting performance.

By being part of the same organization, the different units fall under a hierarchical control system that can facilitate the transfer of information and knowledge. Research by Knott (2001), for example, shows that franchisees that become independent are typically outperformed by those that remain members of the franchise. This appears to be true even for those firms having knowledge of the franchise operation procedures and controlling for size and other benefits that can be derived from being part of the franchise. This somewhat counter-intuitive finding suggests that the potential costs of increasing bureaucratization are outweighed by gains in information accessibility and timeliness.

BEST PRACTICES ADOPTION. The hierarchical structure of a larger (merged) firm can provide the channels and control systems that facilitate the adoption of preferred practices across units; especially if managers design incentives to favor their adoption. For a manager in charge of an autonomous business, engaging in change may not be justified because of the risk of failure and the cost of engaging in the change. However, when the same manager is in charge of the same 
business but now as a part of a larger organization through acquisition, the risk of failure is distributed over a wider set of units within the whole organization. In addition, other units within the larger organization can be called upon to transfer their experiential learning in support of the manager's change effort, thus reducing costs of learning and the risks of failure. In fact, under these circumstances it may be more costly not to engage in change.

Hierarchical control combined with more complete information available to managers provides an environment where it is in theory easier to achieve change and adopt best practices. Evidence from the field of medicine is illustrative. Treatment models emphasizing combinations of methods (training primary care physicians, patient education, on-site consultation by mental health specialist, and close medication adherence and case management monitoring) have been found to be more likely to promote the adoption of new practices and guidelines than those models relying in single methods (such as mailing lists, or training primary care physicians) and to have better patient outcomes (Katon et al., 1999; Katzelnick et al., 2000; Rubenstein et al., 1999; Simon, VonKorff, Rutter, \& Wagner, 2000).

\section{POTENTIAL BENEFITS OF CONSOLIDATION IN ADDICTION TREATMENT}

Consolidation has begun in the addiction treatment industry ("Creative Socio-Medics Parent Acquires CMHC," 2005; Jackson, 2005a, 2005b, 2005c) and it has the potential to improve 
efficiency and effectiveness in the industry substantially. What benefits might we anticipate from consolidation in the addiction treatment industry? In discussing the potential benefits of railroad consolidation in the 1920s, Daniel (1924) argued that "in the absence of any even approximate estimate of the economies under consolidation it becomes at once speculative to guess at the degree in which net economies would result..." What was true for railroads 80 years ago is just as true for addiction treatment today; it is impossible to predict with certainty how consolidation will affect economies in the addiction treatment field. However, it is clear that the benefits that may accrue from consolidation in addiction treatment are not just economic (mainly achieved through cost reduction), but also lie in improvements in quality and performance (achieved by adoption of best practices and technology). And if addiction treatment is effective, then its benefits would be felt on a much wider basis as former addicts resume productive social roles at work, in their families, and in their neighborhoods.

\section{COST IMPROVEMENT}

\section{Insurance and Medicare pressure}

The current dependency of addiction treatment centers on payments from Medicare and Medicaid - often acting through intermediary Managed Care Organizations - presents a strong incentive for consolidation in the industry. Reduced costs of collection and simplified payment systems can be achieved by consolidation thereby improving the addiction treatment centers' negotiating position with payers and reducing the number of actors they have to deal with.

\section{New technologies and practices}


McLellan argues that the diffusion of evidence-based treatments such as new medications, therapies and interventions in addiction treatment in general has been disturbingly slow. Research by Mark and colleagues (2003) confirms this view. Were a number of SAT centers consolidated and integrated into a hierarchy, the headquarters could facilitate adoption of improved treatment models. By managing incentives for addiction treatment center managers, headquarters could promote the implementation of treatment-oriented evidence-based practices.

\section{Improved administrative routines}

A variety of studies in different states has shown that there is wide room for improvement in the adoption of improved administrative routines. Some of these include shorter times between first contact (telephone) with the treatment center, and improved customer service practices to support patient retention (See Gustafson et al., 2005). A consolidated hierarchical structure can provide the means to insure the adoption of such routines.

We expect to find sizeable gains from consolidation in these three areas. Consolidation should reduce the cost of transactions by centralizing the administration of the collection of account receivables. Consolidated firms should be able to leverage the potential inherent in innovations in information technology since they will be able to invest in more sophisticated systems. The adoption of new treatments has the potential to improve outcomes, reducing recidivism and length of treatment. Improved administrative routines have the potential to affect many aspects in the organization, from the number of patients with access to the service, to the length of service, to patient retention. These factors can have a large impact on the economics of the business on both the cost and the revenue side. 
Although the potential benefits of consolidation in the addiction treatment industry are considerable, there is no guarantee that the benefits will be realized. However, we expect that the combination of cost reduction and revenue increases will result in greater efficiency and effectiveness at the level of individual SAT centers and greater overall value for patients and society as a whole.

At the state level, regulatory changes can lead to similar results by imposing requirements for participation in state-funded initiatives on the addiction treatment centers. For example, by linking participation in the state substance abuse treatment programs to the adoption of evidencebased treatments and managerial best practices, the State of Delaware has been able to improve efficiency and effectiveness of the substance abuse treatment facilities statewide (Kemp, 2005).

\section{MARKET STRUCTURE}

\section{Pros AND Cons of DiffERENT MARKET StRUCTURES: What Do We KNOW?}

Structure by itself provides no guarantee of success or failure, as the examples we will present shortly demonstrate. Market structures open different possibilities and the ability to achieve certain goals. While a decentralized, fragmented market structure favors experimentation and the finding of new business opportunities, a concentrated market facilitates the exploitation of developed knowledge and the adoption of best practices consistently across the board.

Concentration is the result of a few firms controlling most of the market, and that is only realized by achieving above-average efficiency. The dominant firms in an industry tend to adopt state-of- 
the-art technologies and managerial practices and to be able to implement them, something that smaller firms are not prone to do because of their size constraints, greater risks relative to gains, and other inertial forces.

Following Thompson's (1967) seminal work, management researchers have studied how the benefits of centralized versus decentralized decision making structures depend on the contingencies faced by the organizations. Recent studies based on simulations have shown that decentralized decision-making reaches higher payoffs when knowledge is uncertain and exploration is widespread. However, in later stages, centralized decision-making obtains superior returns as what is known to be a superior strategy is broadly and widely exploited (Siggelkow and Levinthal, 2003; Rivkin and Siggelkow, 2003, Siggelkow and Rivkin, 2005). Hierarchies, with the information they access from their subunits, obtain a more comprehensive picture and are able to select and adopt the solutions with the higher payoffs, be they technical or administrative. In addition, they can facilitate information exchange across units, which smoothes the process of adopting best practices. Siggelkow and Levinthal (2003) also show that organizations benefit from moving from centralization to decentralization when the environment changes and exploration of new alternatives is needed. Following this logic, we posit that the addiction treatment industry is in a stage where centralization is beneficial. Centralization can help spread what the industry has learned by selecting the solutions that provide higher "payoffs," as we will argue in the following paragraphs.

Hierarchical organization provides control systems that facilitate the adoption of new, innovative technologies and practices. Headquarters can establish incentives, training, information sharing, 
and follow up systems to facilitate the diffusion and adoption of change by lower level management; incentives and systems that are usually not present when the manager acts independently. To illustrate, we use two examples from the agricultural sector. First is the case of a dairy product organization in Uruguay. Until the 1930s, the market for dairy products in Uruguay was highly fragmented, with a large number of independent milk producers processing milk supplied by themselves and other small producers. Quality was mixed, and, overall, this system created a health risk, since the state found it impossible to impose and control sanitary conditions. In 1936, the Uruguayan government promoted the creation of CONAPROLE (a cooperative of milk producers) with a mixed ownership structure (a board with representation of the state and the producers) as an umbrella under which most of the producers were incorporated. Small milk producers remained the owners of the production facilities, but obtained access to lower cost credit, technological support, and a buyer for their milk production from CONAPROLE. CONAPROLE concentrated milk processing into 2 plants, which allowed the cooperative to invest in new technology, improving quality and safety of dairy products. Seventy years later and operating 8 plants, CONAPROLE became the Uruguayan top exporter of dairy products, having been able to access and compete in European and Latin-American markets. Consolidation, driven by the government, enabled technological innovation and the development of capabilities that made the Uruguayan dairy industry a viable competitor in world markets. Our second example is the wine industry in Mendoza, Argentina. Argentina has made itself a player in the world wine market in the last 10 years, going from almost zero to capturing $2.5 \%$ of the world market (McDermott, 2005). A province located by the Andes Mountains, on the border with Chile, Mendoza's largest winery was run by the provincial government and produced wine of low quality in a province where private wineries and vineyards were abundant. The private 
wineries and vineyards had a long tradition with some of them being considered the best in Argentina. The wine from those private wineries has been compared favorably to good Chilean wines. In the late 80s, the Government of Mendoza decided to spin-off its winery and vineyards and created FECOVITA, a cooperative with mixed ownership structure (grape producers, winery and provincial government have representation on the board). The ownership of the land was given to the grape producers (a large number of small vineyards in the eastern zone). The winery was put under control of FECOVITA. In 10 years, this winery became one of the best in the province, exporting wine that has been recognized among the best by Wine Spectator.

FECOVITA became a facilitator of state-of-the-art technology adoption by the vineyards. New varietals and quality improvement are the foundation of FECOVITA's wines success.

This example illustrates the point that it is not the structure per se but how it is implemented that makes a difference. Before the inception of FECOVITA, the same vineyards, winery and people were involved in the production of wine in a hierarchical structure. This organization, managed by an inefficient bureaucratic system, was unable to take advantage of the opportunities that were available. In the next section we draw a second lesson from the Mendoza wine industry experience: the importance of institutions and how government can support the transfer of knowledge and adoption of innovation.

PROMOTION OF KNOWLEDGE TRANSFER AND ADOPTION OF INNOVATION AT THE INDUSTRY LEVEL: WHAT DO WE KNOW?

The case of the wine industry in Mendoza is also illustrative of how institutions can support the sharing of knowledge and adoption of innovations by firms. In his comparative study of the provincial wine industry, McDermott (2005) presents evidence of the effect of two different 
approaches to the promotion of technology transfer and adoption of best practices. While both Mendoza and San Juan provinces were similar in almost every aspect that affected wine production (climate, economic development, population, etc.), they were quite different with regard to the approach taken by their provincial governments. San Juan's government based its industrial policy on economic incentives (tax breaks, favorable regulation, etc.), while Mendoza's government engaged in the creation of public-private institutions, which provided deliberative forums for improving public policy and favored collective action.

Mendoza's government created inclusive public-private institutions, aiming to solve particular problems found by organizations in the sector, where the relevant industry actors were integrated together with the provincial government. When new problems surfaced, new institutions with the same philosophy were created. This process created institutions that provided forums for discussion that integrated members of isolated clusters and facilitated collective action. In addition, the manner by which members were brought into these institutions guaranteed the creation of many ties among institutions. As a result, the transfer of experiential knowledge and information across social and geographic distances was facilitated and promoted. The experimentation with new technology and the flow of information across firm boundaries made possible a broad technological and managerial revolution. Another important advantage of this evolution is that it appears to have reduced variability across different growers. In Mendoza's most backward region, even the least developed growers have caught up with the best in the province. Similar results were not achieved by San Juan. The economic incentives, while yielding isolated success cases, were not able to bridge the gap between different sectors of its 
wine industry and knowledge remained localized within only a few firms without reaching the rest of the industry.

This story of competition-cooperation in the case of vineyards and wineries in Mendoza is important to highlight. Commercial relationships between grape producers and wineries are informal and not ruled by contracts. The lack of long term contracts exposes the producers and wineries to opportunistic behavior from the counterpart. For example, vineyards may be forced to accept lower prices for their grapes because the investment made to grow the grapes according to winery specifications may not be reflected in the price for other buyers. However, in general, the relationships between producers and wineries are characterized by cooperation. Even though competition in local markets is strong, cooperation between wineries or producers is still present and knowledge spillovers are common because participants compete together in the larger world market as Argentinean wine producers. There are also economies from participating in a high quality cluster. Quality of the wine is defined by the lowest quality of the grapes used in production; hence any quality improvement in varietals will only result in better wine when all the producers supply similar, high quality grapes. Limited competition, interdependence between producers and wineries, and an institutional structure that leads to dense networks of firms can generate an atmosphere that is conducive to cooperation among firms within the industry.

\section{DOES ANY OF THIS APPLY TO ADDICTION TREATMENT INDUSTRY?}

Why is this relevant to the addiction treatment industry? Several similarities between the wine industry in Mendoza and the contemporary addiction treatment industry should be noted. First, 
competition between centers is quite limited to geographically proximate organizations.

Although a few customers may go to centers that are distant, in general this is not the case.

Studies have estimated that customers for hospitals are drawn from the population in a 100 mile radius. In the case of addiction treatment centers, this distance is likely to be much shorter. This could reduce limits on information sharing with other members of the industry.

Second, like the addiction treatment field vineyards and wineries were not a concentrated industry by any means. There were thousands of grape producers and more than 200 wineries in Mendoza province alone. The majority of the vineyards were small firms, with a size that made acquisition of high technology machinery not profitable. In the addiction treatment field, as McLellan and Meyers (2004) point out, treatment centers are generally small, lacking expensive, technologically advanced staff (physicians, psychologists, social workers) and it is not uncommon for them to be run by part-time managers with little formal training in administration.

Third, in general, addiction treatment centers appear to be quite isolated, which limits their ability to learn from the experiences of others, a situation prevalent in Mendoza wine industry during the 1980s. The isolation is not limited to the lack of interaction with other centers, but also with institutions such as research centers, medical schools, and other health care organizations (McLellan, 2002; McLellan \& Meyers, 2004). The creation of institutions to bring these organizations together into forums opens the opportunity for collective action. It has the potential to facilitate transfer of experiential knowledge between the participants, and to encourage the adoption of best practices and evidence-based technologies. 


\section{ADDICTION TREATMENT INDUSTRY STRUCTURE}

The addiction treatment industry is characterized by a large number of small centers that draw their patients from relatively small geographic areas. In recent years, and mainly promoted by the drive to cut costs, these centers have begun to face strong pressures to increase their efficiency. The health care sector has already experienced this push, resulting in consolidation within the hospital industry, and it appears that consolidation in the addiction treatment industry is imminent.

Until recently, the market structure could be represented by Figure 3. A state or federally funded office paid a multitude of small centers without any interaction beyond the financial relationship, leaving administrative and technical management in the hands of the centers. More recently, states have started to experiment with Managed Care Organizations to administer their addiction treatment programs, which led to efforts to cut costs and improve efficiency while maintaining access to those in need (Figure 4 represents this structure). This development may have been the initial signal of serious consolidation in the industry. Under a consolidation scenario, we would expect several behavioral health programs to be grouped together within a single behavioral service network of centers specialized in different areas. A recent example is the CRC Health Group (Jackson, 2005b) which now owns 110 addiction treatment centers in more than 20 states, providing drug and alcohol treatment services in residential, outpatient and methadone maintenance clinics. At the state level there are now many carve-out managed care organizations such as MHMA (subsidiary of First Mental Health, Inc) in Massachusetts, Iowa's substance abuse carve-out (IMSACP), and the Arizona Health Care Cost Containment System are forces for standardization. It would seem that Managed Care has the potential to improve the efficiency 
and to help diffuse technology in the treatment of substance abuse patients, and to foster the spread of evidence-based clinical practices.

Based on our studies of other industries, as well as some knowledge of the forces currently operating within the addiction treatment field, we expect the emergence of large organizations with treatment centers covering larger geographical areas (regional or national) specializing in particular treatments, taking advantage of improved managerial practices and facilitating the adoption of evidence based technologies. We expect that the large organizations will have strong economic incentives to adopt standardization, which will in turn promote efficient monitoring and control of both the clinical and administrative processes. Independent addiction treatment centers are unlikely to disappear completely, however. If, the scenario described above actually occurs, it could in turn constrain the number and flexibility of treatment programs and leave some market spaces without coverage. Those conditions could create room for small, flexible organizations. The structure we expect to result from this dynamic in the market is represented in Figure 5. This market structure is already present in many industries and has been extensively studied by Caroll and colleagues (Baum \& Haveman, 1997; Baum \& Korn, 1996; Baum \& Mezias, 1992; Baum \& Singh, 1994; Carroll, 1985). To cite but one example, the newspaper industry is characterized by the presence of a small number of national newspapers and a large number of local newspapers in dynamic equilibrium, effectively partitioning the market into generalists - national newspapers - and specialists - local newspapers (Carroll, 1985). 


\section{INSERT FIGURES 4, 5 ABOUT HERE}

Change in the industry is likely to be generated through both competition - bottom-up forces and mimetic - top-down forces (DiMaggio \& Powell, 1983). Large firms, because of their ability and incentives to adopt state-of-the-art technology and business practices, are likely to become first movers and may serve as a model to the rest of the industry. Other firms will then have a template to imitate and learn from. Competition is a powerful incentive, and to avoid falling behind, other firms mimic the behavior of the more successful ones. Consolidated firms could then set the standard by which all the firms will be measured and constituencies (patients and payors) will impose those standards on the rest of the industry. The force of the constituencies is

likely to push others into adopting those practices and technologies. Managed care organizations may play a crucial role in this process, by imposing qualifying requirements across the industry.

In addition, we expect that, as institutions such as managed care organizations impose demands on the industry to introduce change, forums promoting interaction among addiction treatment centers and between the centers and the states will be created, leading to further diffusion of best practices in both the managerial and clinical domains. 


\section{CONCLUSION}

To summarize, if the history of industry evolution is any guide, we can expect that consolidation will occur within the addiction treatment industry through changes in managed care organizations and through acquisition of small programs by a few well-capitalized firms. In turn, we expect that these consolidated organizations will become catalysts for adoption of innovation, leading to improvements in efficiency and quality across the addiction treatment industry. As early adopters, consolidated firms will show what can be done, moving knowledge from the realm of theoretical to actionable, setting the standards and serving as templates for others. Other, smaller programs may mimic the practices of these larger leading firms so as not to fall behind. Meanwhile, changes in the managed care industry may make managed care organizations the agents of coercive change, forcing all programs in their control to adopt the new industry standards. Such forces may push reluctant firms to adopt innovations, which is likely to improve the efficiency and quality of their services.

While improvements in both efficiency and quality are certainly possible as an industry consolidates, they are not inevitable. Ownership may make a difference. Private, for-profit enterprises, for example, may emphasize improvements in efficiency to a greater extent than improvements in quality. Enterprises that are publicly traded will face pressures to maintain or grow quarter-to-quarter earnings and share price and may be tempted to emphasize cost control as a result. On the other hand, not-for-profit enterprises may lack the kind of managerial sophistication and discipline that would yield greater efficiencies. Thus the links between consolidation and improvements in quality and efficiency are not necessarily direct. 
We see this as the likely story of industry evolution driven by forces within the field. There is, however, always the potential for fundamental transformation driven by a brand new technology (medications, monitoring technology, etc.) or business model developed by an industry or a firm outside the addiction treatment field. Regardless of which forces occur and in which order, it is clear that those very structures we see emerging today will themselves be challenged as the evolutionary story in addiction treatment continues to unfold tomorrow.

\section{REFERENCES}

Baum, J. A. C., \& Haveman, H. A. (1997). Love thy neighbor? Differentiation and agglomeration in the Manhattan Hotel industry, 1898-1990. Administrative Science Quarterly, 42(2), 304.

Baum, J. A. C., \& Korn, H. J. (1996). Competitive dynamics of interfirm rivalry. Academy of Management Journal, 39(2), 255.

Baum, J. A. C., \& Mezias, S. J. (1992). Localized competition and organizational failure in the Manhattan hotel industry, 1898-1990. Administrative Science Quarterly, 37(4), 580.

Baum, J. A. C., \& Singh, J. V. (1994). Organizational niches and the dynamics of organizational founding. Organization Science, 5(4), 483.

Carroll, G. R. (1985). Concentration and specialization: Dynamics of niche width in populations of organizations. American Journal of Sociology, 90(6), 1262-1283.

Christensen, C. M. (1997). The innovator's dilemma : when new technologies cause great firms to fail. Boston, Mass.: Harvard Business School Press.

Creative Socio-Medics Parent Acquires CMHC. (2005). Treatment Magazine, Nov 2005, 14.

Daniels, W. M. (1924). Economic Purposes and Limitations of Consolidation. The Journal of Economic Review, 14(1, Supplement, Papers and Proceedings of the Thirty-sixth Annual Meeting of the American Economic Association), 43-51.

DiMaggio, P. J., \& Powell, W. W. (1983). The iron cage revisited: Institutional isomorphism and collective rationality in organizational fields. American Sociological Review, 48(2), 147-160.

Gustafson, D. H., Capoccia, V. A., Molfenter, T., Cotter, F., Cassidy, E. F., Ford, J., et al. (2005). Building organizational improvement capacity while improving addiction treatment: the network for the improvement of addiction treatment.Unpublished manuscript.

Huckman, R. S., \& Pisano, G. P. (forthcoming). The Firm Specificity of Individual Performance: Evidence from Cardiac Surgery. Management Science. 
Jackson, T. (2005a). The CEOs Speak: What Role Will the Prestige Foundations Play in the Consolidation Wave. Treatment Magazine, 35-36.

Jackson, T. (2005b). On a Rollup... CRC Health Group. Treatment Magazine, July 2005, 25-28.

Jackson, T. (2005c). There's Nothing Constant but Change. Treatment Magazine, July 2005, 8.

Katon, W., Von Korff, M., Lin, E., Simon, G., Walker, E., Unutzer, J., et al. (1999). Stepped Collaborative Care for Primary Care Patients With Persistent Symptoms of Depression: A Randomized Trial. Arch Gen Psychiatry, 56(12), 1109-1115.

Katzelnick, D. J., Simon, G. E., Pearson, S. D., Manning, W. G., Helstad, C. P., Henk, H. J., et al. (2000). Randomized Trial of a Depression Management Program in High Utilizers of Medical Care. Arch Fam Med, 9(4), 345-351.

Kemp, J. (2005, Nov. 2005). Delaware's performance contracting experiment. Paper presented at the The Wharton-TRI Conference on the Business of Addiction Treatment: Industry Consolidation and its Implications, Philadelphia, PA.

Knott, A. M. (2001). The dynamic value of hierarchy. Management Science, 47(3), 430-448.

Mark, T. L., Kranzler, H. R., \& Song, X. (2003). Understanding US addiction physicians' low rate of naltrexone prescription. Drug and Alcohol Dependence, 71(3), 219-228.

McDermott, G. A. (2005). The Politics of Institutional Renovation and Competitive Upgrading: Lessons from the Transformation of the Argentine Wine Industry.Unpublished manuscript.

McKelvey, P. (1999). The ties that bind in roll-up plays that work. Mergers \& Acquisitions: The Dealermaker's Journal, 33(6), 37.

McLellan, A. T. (2002). Technology transfer and the treatment of addiction: what can research offer practice? Journal of Substance Abuse Treatment, 22(4), 169-170.

McLellan, A. T., \& Meyers, K. (2004). Contemporary addiction treatment: A review of systems problems for adults and adolescents. Biological Psychiatry, 56(10), 764-770.

Pisano, G. P., Bohmer, R. M. J., \& Edmondson, A. C. (2001). Organizational Differences in Rates of Learning: Evidence from the Adoption of Minimally Invasive Cardiac Surgery. Management Science, 47(6), 752.

Rubenstein, L. V., Jackson-Triche, M., Unutzer, J., Miranda, J., Minnium, K., Pearson, M. L., et al. (1999). Evidence-based care for depression in managed primary care practices. Health Aff, 18(5), 89-105.

Simon, G. E., VonKorff, M., Rutter, C., \& Wagner, E. (2000). Randomised trial of monitoring, feedback, and management of care by telephone to improve treatment of depression in primary care. $B M J$, 320(7234), 550-554.

Szulanski, G. (2001). Appropriability and the Challenge of Scope: Banc One Routinizes Replication. In G. Dosi, R. R. Nelson \& S. Winter (Eds.), The Nature and Dynamics of Organizational Capabilities (pp. 69-98). Oxford: Oxford University Press. 
Thompson, J. D. (1967). Organizations in action, social science bases of administrative theory. New York: McGraw-Hill.

Tripsas, M., \& Gavetti, G. (2000). Capabilities, cognition, and inertia: Evidence from digital imaging. Strategic Management Journal, 21(10/11), 1147.

Winter, S. G., \& Szulanski, G. (2001). Replication as Strategy. Organization Science: A Journal of the Institute of Management Sciences, 12(6), 730. 
Figures

\section{Figure 1. Strategic Objectives in Industry Roll-Ups}

\begin{tabular}{|l|l|l|}
\hline \multirow{2}{*}{$\begin{array}{l}\text { Economies of } \\
\text { Scale }\end{array}$} & Health Clubs & $\begin{array}{l}\text { Combined "back-office" procedures are more } \\
\text { efficient than individual club departments }\end{array}$ \\
\cline { 2 - 3 } Value-Cost & Funeral Services & $\begin{array}{l}\text { Centralized purchasing of caskets and flowers } \\
\text { to achieve better pricing }\end{array}$ \\
\hline Leveraging & Temporary Help & $\begin{array}{l}\text { Consolidated data entry, billing, hiring, and } \\
\text { resume searching reduces costs and ensures } \\
\text { customers the most appropriate help }\end{array}$ \\
\cline { 2 - 3 } Redefining & Veterinary Services & $\begin{array}{l}\text { Uniform operating and pricing policies } \\
\text { simplify procedures and reduce customers' risk } \\
\text { and uncertainty }\end{array}$ \\
\cline { 2 - 3 } Product or Service & Gagers & $\begin{array}{l}\text { Adequate financing enables doubled capacity } \\
\text { with multi-level grandstands }\end{array}$ \\
\cline { 2 - 3 } & Golfing Ranges & $\begin{array}{l}\text { National service is far more valuable than } \\
\text { independent regional operators }\end{array}$ \\
\hline
\end{tabular}

Source: McKelvey, P. 1999. The ties that bind in roll-up plays that work. Mergers \& Acquisitions: The Dealermaker's Journal, 33(6): 37. 
Figure 2. Screening Targets for the Roll-Up

\begin{tabular}{|l|l|l|}
\hline \multicolumn{1}{|c|}{$\begin{array}{c}\text { EXAMPLE ROLL-UP } \\
\text { STRATEGY }\end{array}$} & \multicolumn{1}{c|}{$\begin{array}{c}\text { INDUSTRY } \\
\text { EXAMPLE }\end{array}$} & SAMPLE ACQUISITION CRITERIA \\
\hline $\begin{array}{l}\text { SG\&A Rationalization } \\
\text { Opportunity }\end{array}$ & Legal Services & $\begin{array}{l}* \text { High SG\&A as a of sales } \\
* \text { Overhead functions can be centralized }\end{array}$ \\
\hline Purchasing Power & Funeral Services & $\begin{array}{l}* \text { High COGS as a \% of sales } \\
* \text { Small/medium-sized companies with } \\
\text { little purchasing power }\end{array}$ \\
\hline $\begin{array}{l}\text { Marketing } \\
\text { Advantages/Brand Name }\end{array}$ & Health Clubs & $\begin{array}{l}* \text { Location(s) within regional cluster } \\
\text { corporate strategy }\end{array}$ \\
\hline $\begin{array}{l}\text { Opportunities to leverage } \\
\text { advanced information } \\
\text { technology systems }\end{array}$ & Temporary Help & $\begin{array}{l}* \text { Operating procedure which can be } \\
\text { made efficient through MIS technology }\end{array}$ \\
\hline $\begin{array}{l}\text { Ability to attract professional } \\
\text { management }\end{array}$ & Lawn Care & $\begin{array}{l}* \text { Underperforming services organization } \\
\text { (e.g., marketing, operations, etc.) within } \\
\text { limited general management capabilities }\end{array}$ \\
\hline
\end{tabular}

Source: McKelvey, P. 1999. The ties that bind in roll-up plays that work. Mergers \& Acquisitions: The Dealermaker's Journal, 33(6): 37. 
Figure 3. Applying McKelvey's Analysis to the Addiction Treatment Industry

\begin{tabular}{|c|c|c|}
\hline ISSUE & FACTORS TO CONSIDER & Addiction Treatment Industry \\
\hline \multirow{3}{*}{$\begin{array}{l}\text { Value Chain } \\
\text { Analysis }\end{array}$} & Economies of scale & Reduced administrative costs, \\
\hline & Value-cost leveraging & $\begin{array}{l}\text { More efficient technology can reduce costs and } \\
\text { increase value }\end{array}$ \\
\hline & Product or service redefinition & $\begin{array}{l}\text { Sustainable competitive advantage can be } \\
\text { provided by location }\end{array}$ \\
\hline \multirow{3}{*}{$\begin{array}{l}\text { Platform } \\
\text { Availability }\end{array}$} & Replicable, efficient operating model & $\begin{array}{l}\text { Evidence-based treatments and administrative } \\
\text { practices }\end{array}$ \\
\hline & Proven success & $\begin{array}{l}\text { States experience with Managed Care, Gustafson } \\
\text { and colleagues study }\end{array}$ \\
\hline & $\begin{array}{l}\text { Cultural fit and committed } \\
\text { management }\end{array}$ & \\
\hline \multirow{3}{*}{$\begin{array}{l}\text { Add-On } \\
\text { Availability }\end{array}$} & Large number of available targets & $13,000 \mathrm{SAT}$ centers \\
\hline & $\begin{array}{l}\text { Adequate average revenue per } \\
\text { company }\end{array}$ & \\
\hline & $\begin{array}{l}\text { High level of value-creation per } \\
\text { acquisition }\end{array}$ & $\begin{array}{l}\text { Large proportion with room for improvement } \\
\text { (treatments and administration) }\end{array}$ \\
\hline \multirow{3}{*}{$\begin{array}{l}\text { Cost of Due } \\
\text { Diligence }\end{array}$} & Standard business model & Targets are small and tractable \\
\hline & Predictability of revenues and costs & Stable market and demand \\
\hline & $\begin{array}{l}\text { Low probability of extraordinary cost } \\
\text { (litigation risk) }\end{array}$ & $\begin{array}{l}\text { No clear reason for increased risk from } \\
\text { consolidation }\end{array}$ \\
\hline
\end{tabular}

Adapted from McKelvey, P. 1999. The ties that bind in roll-up plays that work. Mergers \& Acquisitions: The Dealermaker's Journal, 33(6): 37. 


\section{Current Structures:}

Figure 4

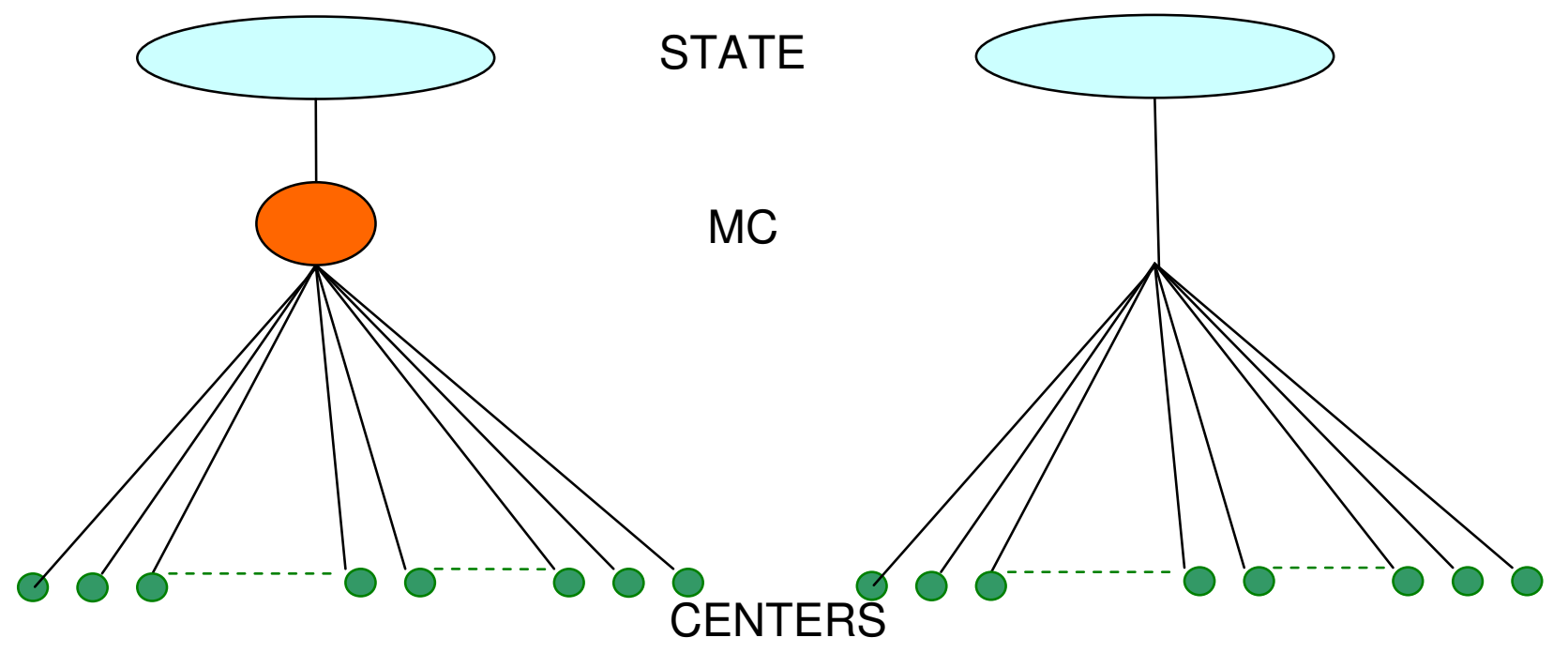

Predicted Structure:

Figure 5

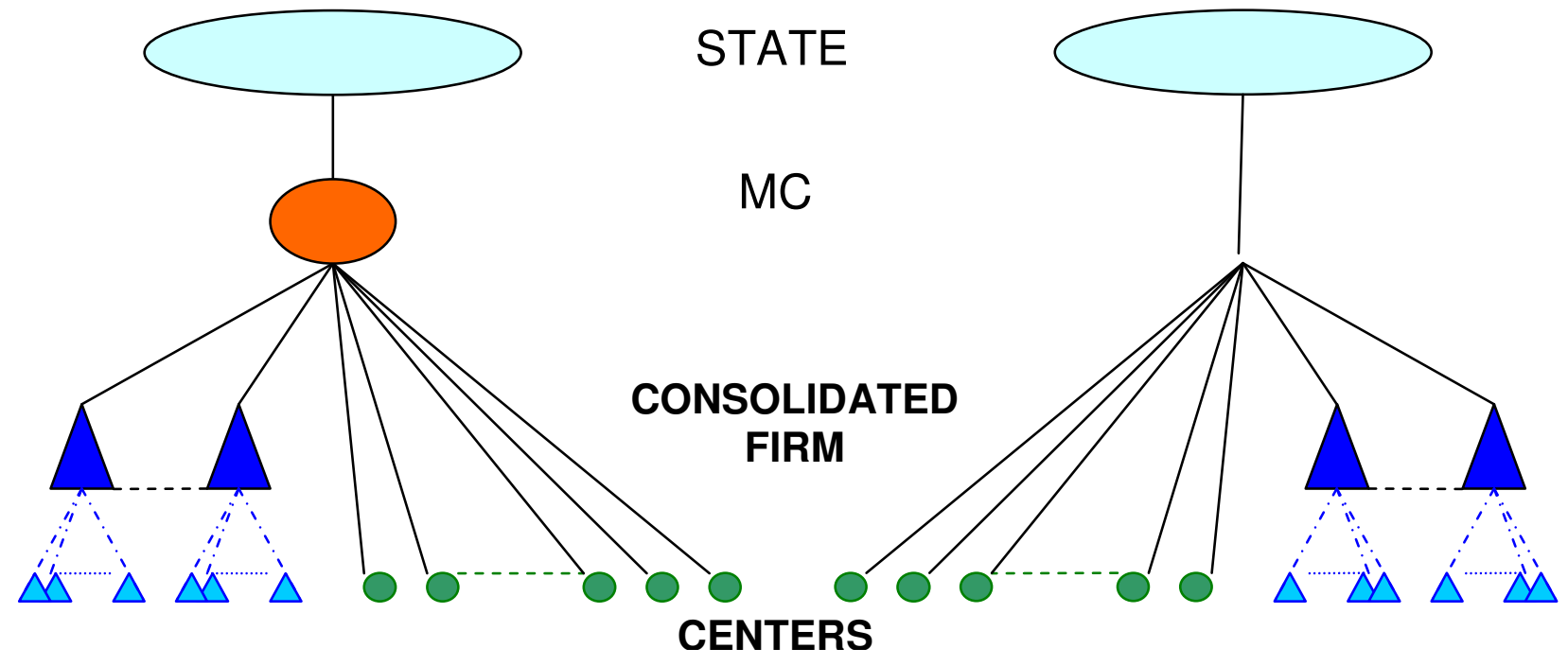

